\title{
A Review of Blood Transfusion Requests in Rl Jalappa Hospital and Research Centre for Blood and Blood Components
}

Venkatachalapathy TS $^{1 *}$ and Subhashish Das ${ }^{2}$

${ }^{1}$ Sri Devaraj URS Medical College, Tamaka, Kolar, 563101, Karnataka, India

${ }^{2}$ Sri Devaraj URS Medical College, I/C Blood Bank, RI Jalappa Hospital And Research Centre, Tamaka, Kolar, 563101, Karnataka, India,

\begin{abstract}
Predetermined transfusion guidelines, pretransfusion approval, and transfusion audits are useful tools in the education of those ordering blood components, potentially resulting in the reduction of inappropriate use of blood components. In spite of advice by the blood bank physician, blood components released based on the demand of the ordering physician, which was deemed as inappropriate transfusions. The present study was conducted upon 1694 episodes of transfusion units for different blood components over a period of 3 months from November 2011 to January 2012. Of the total 1694 transfusion episodes in 920 requests for 796 patients. 124 patients had multiple requests. 208 males and 588 were females. Single unit requisitions were 456, and two unit requisitions were 354 , and 3 or more unit requisition in 110 requests. 222 requests contained $>10 \mathrm{gms} \%$ as indication, 330 requests had $7.1-9.9 \mathrm{gms} \%$, and 250 requests with $<7 \mathrm{gms} \%$. Elective transfusion requests found in 100 requests and 369 had emergency request, and 451 didn't contain any information. 136 patients received single unit transfusion. 660 patients had 2 or more than 2 unit transfusion. During this 3 month period 20.3 units /day was bled at blood bank and in camps. 26.4 units/day issued to both Inpatient (IP) and Outpatient (OP) requests. 18.4 units/day was issued to IP requests. 450 requests from Obstetrics and Gynecology (OBG) department, 735 requests had indication for blood transfusion written in the requisition. The objective of this study is prospective audits of blood component orders can help reduce inappropriate transfusions and can be a valuable educational tool for the ordering physicians as well as for residents in training.
\end{abstract}

Keywords: Blood components; Tertiary hospital; Audit

\section{Introduction}

The blood component implies separation of whole blood into various potential components like packed red cells,

Platelet rich plasma, fresh frozen plasma, cryoprecipitate and leucocytes [1-4]. Blood and its components are an important part of patient management treatment protocols and like drugs, have property to cause adverse reactions in the recipients. To maximize the effectiveness, safety, and utility clinicians and intravenous therapists should be knowledgeable about the potential risk of blood component therapy [5].

Therefore the clinician should keep in mind the appropriate indication for ordering blood components there by avoid misuse and unnecessary exposure of the recipient to various infectious and non infectious complications. Hence, regular audit of blood and its component usage is essential to access the blood utilization pattern and set ideal policies in all the blood using specialties. In spite of the sophisticated blood banking services worldwide; indiscriminate use of blood components with either no indication or inappropriate indication continues.

Clinical audit is a management tool for the appraisal and justification of appropriateness and efficiency of transfusion therapy [2], and an important part of the quality assurance programme which can provide necessary information for improving transfusion medicine practice1. Adequate documentation of evidence to support a rationale for blood transfusion is considered an essential part of transfusion medicine. More complete and appropriate documentation allows more transfusion episodes to be assessed in an audit [2,3]. Transfusion is considered appropriate when it is used to treat conditions leading to significant morbidity and mortality and which cannot be prevented or managed effectively by other means [3]. Various strategies have been developed to reduce the inappropriate use of blood components. These include guidelines and consensus conferences as well as monitoring of transfusion practice, education, and self-audit by clinicians [4].

\section{Materials and Methods}

This prospective study was conducted at RL Jalappa Hospital and research centre, attached to Sri Devaraj URS medical college, Tamaka, Kolar, India [6,7]. It was done over a period of 3 months from November 2011 to January 2012. A prospective analysis of blood and its component requisitions in all patients from different clinical departments were reviewed regarding diagnosis, indication for transfusion, number of units requested and the speciality prescribing it. Reports of silent investigations like hemoglobin, platelet count, coagulogram were also recorded. Nature of component and their quantity used was correlated with disease indication for transfusion of a particular component using pre tested questionnaire $[8,9]$.

\section{Results}

The present study was conducted upon 1694 episodes of transfusion units for different blood components over a period of 3 months from November 2011 to January 2012. Of the total 1694 transfusion episodes

*Corresponding author: Venkatachalapathy TS, Sri Devaraj URS Medical College, Tamaka, Kolar, Karnataka, India, 563101, Tel: +918197507094; E-mail: drvenkey@hotmail.com

Received February 27, 2012; Accepted March 19, 2012; Published March 25 , 2012

Citation: Venkatachalapathy TS and Das S (2012) A Review of Blood Transfusion Requests in RI Jalappa Hospital and Research Centre for Blood and Blood Components. J Blood Disord Transfus 3:119. doi:10.4172/2155-9864.1000119

Copyright: () 2012 Venkatachalapathy TS. This is an open-access article distributed under the terms of the Creative Commons Attribution License, which permits unrestricted use, distribution, and reproduction in any medium, provided the original author and source are credited. 
Citation: Venkatachalapathy TS and Das S (2012) A Review of Blood Transfusion Requests in RI Jalappa Hospital and Research Centre for Blood and Blood Components. J Blood Disord Transfus 3:119. doi:10.4172/2155-9864.1000119

Page 2 of 3

in 920 requests for 796 patients. 124 patients had multiple requests. 208 males and 588 were females (Tables 1-4).

145 were whole blood, 912 were packed cells, 306 were platelet concentrate, and 331 were Fresh Frozen Plasma (FFP). Single unit requisitions were 456, and two unit requisitions were 354 , and 3 or more unit requisition in 110 requests. 222 requests contained $>10$ gms\% as indication, 330 requests had $7.1-9.9$ gms\%, and 250 requests with $<7$ gms\%. 118 requests didn't contain any information. Regarding $\mathrm{Hb}$. Elective transfusion requests found in 100 requests and 369 had emergency request, and 451 didn't contain any information.

Platelet count was written in 55 patients (306) and 65 patients (331) had FFP transfusion.

Out of 796 patients 120 patients received 145 units of whole blood, 556 patients received 912 units of packed cells, Out of 920 requests 860 requests had blood grouping written on the requisition.

136 patients received single unit transfusion. 660 patients had 2 or more than 2 unit transfusion.

During the 3 month period ,208 units of A positive ,288 units of $B$ positive, $A B$ positive -41 , O positive -322 , A negative -17 , $B$ negative $-20, A B$ negative 1 unit, $O$ negative -23 unit were transfused for 920 requests on 796 patients.

1873 units were donated during the 3 month period both indoor and in camps. 2399 units were issued from blood bank, 705 issued to other hospitals in and around kolar. During this 3 month period 20.3 units /day was bled at blood bank and in camps. 26.4 units/day issued to both IP and OP requests. 18.4 units/day was issued to IP requests.

450 requests from OBG dept , 113 requests from Surgery dept, 145

\begin{tabular}{|l|l|}
\hline Sex & N (\%) \\
\hline Male & $208(26.2)$ \\
\hline Female & $588(73.8)$ \\
\hline Total & $796(100)$ \\
\hline
\end{tabular}

Table 1: Sex distribution.

\begin{tabular}{|l|l|}
\hline Blood group & $\mathrm{N}(\%)$ \\
\hline $\mathrm{A}+\mathrm{Ve}$ & $208(22.60)$ \\
\hline $\mathrm{B}+\mathrm{Ve}$ & $288(31.30)$ \\
\hline $\mathrm{O}+\mathrm{Ve}$ & $322(35)$ \\
\hline $\mathrm{Ab}+\mathrm{Ve}$ & $41(4.45)$ \\
\hline $\mathrm{A}$ Negative & $17(1.84)$ \\
\hline $\mathrm{B}$ Negative & $20(2.17)$ \\
\hline Ab Negative & $1(0.10)$ \\
\hline O Negative & $23(2.5)$ \\
\hline Total & 920 \\
\hline
\end{tabular}

Table 2: Blood group distribution in requests.

\begin{tabular}{|l|l|}
\hline Department & $\mathrm{N}(\%)$ \\
\hline Medicine & $145(15.76)$ \\
\hline Surgery & $113(12.28)$ \\
\hline OBG & $450(48.91)$ \\
\hline Ortho & $102(11.08)$ \\
\hline Paediatrics & $36(3.91)$ \\
\hline ENT & $44(4.78)$ \\
\hline Cardiology & $15(1.63)$ \\
\hline Urology & $15(1.63)$ \\
\hline Total & 920 \\
\hline
\end{tabular}

Table 3: Requests from departments.

\begin{tabular}{|l|l|}
\hline Type Of Component & N UNITS \\
\hline Whole Blood & $145(8.55)$ \\
\hline Packed Cells & $912(53.83)$ \\
\hline FFP & $331(19.53)$ \\
\hline Platelet cocentrate & $306(18.06)$ \\
\hline Total & 1694 \\
\hline
\end{tabular}

Table 4: Blood component distribution.

requests from medicine dept, 102 requests from ortho dept, 36 requests from pediatrics, 44 requests from ENT dept, 15 from cardiology and 15 from urology.

During the last one year 2011, 6433 units were bled at blood bank and camps. (3214 -BB, 3219 -Camps) 14.9 units /day was issued from Blood Bank (BB) to in patients (IP). 21.2 units /day issued to both IP and OP patients. 18.4 units/day was bled at BB and camps.

During this period 3 HIV positive blood units, 13 units were HBs Ag positive, 10 units were $\mathrm{HCV}$ positive. During the last one year 9 HIV positive, $66 \mathrm{HBs}$ Ag positive, 6 units were HCV positive.

Out of 136 patients, more of single unit transfusion occurred in medicine dept, followed by pediatrics, followed by surgery, OBG and $\operatorname{ENT}(45,35,28,18$, and 10).

Out of 920 requests, 185(20.1\%) requests had no indication. The commonest indication in Medicine dept is chronic anemia $80 \%$, in surgery department pre operative and intraoperative transfusion for correction of acute blood loss due to trauma, chronic anemia. In OBG dept commonest indication is Post partum hemorrhage and pre operative correction of anemia. In ortho dept commonest indication is acute blood loss and pre operative correction anemia. In pediatrics main indication was anemia. In ENT main indication was pre op anemia correction, in urology also was anemia.

\section{Discussion}

Internal audits form an integral part of the quality control programme in any blood bank, like in any other organization $[10,11]$. Blood and blood products are considered drugs by the Food and Drug Administration (FDA). Indiscriminate Use of blood components is on a rise due to easy availability of sophisticated blood banking services. It is important for the blood bank to be able to fulfill the demand for this life saving product and at the same time, evaluate and access the existing trends of blood ordering.

The importance of an internal audit and education programme emphasizing proper selection of blood components for patients and avoiding their overuse $[12,13]$. Therefore we tried to look into the transfusion practices in patients at a tertiary care hospital. As a fact the supply of blood and blood components are finite, a high rate of inappropriate use has been reported around the world. This inappropriate use of blood and its components have a significant impact on the patients and the hospital staff in the form of health care cost $[14,15]$, wastage of resources, depriving more needy patients and transmission of infection with unnecessary allergic reaction leading to high mortality and morbidity in patients.

Other issues that must be addressed before a system of prospective monitoring can be introduced include exemption criteria. Some protocols exempt operating room patients, [6] "desperate situations" [14] and hematology and oncology patients [13]. Emergency situations are also usually exempted from the requirement for laboratory data if the laboratory cannot provide urgent results at all times. If the criteria 
Citation: Venkatachalapathy TS and Das S (2012) A Review of Blood Transfusion Requests in RI Jalappa Hospital and Research Centre for Blood and Blood Components. J Blood Disord Transfus 3:119. doi:10.4172/2155-9864.1000119

Page 3 of 3

are to be applied to emergency situations, laboratory facilities must be available to provide the data quickly.

In some programs of prospective monitoring, blood products are never withheld, but apparently inappropriate transfusions are later reviewed $[11,14]$. Refusal to issue blood products leads to an adversarial relationship between clinicians and laboratory staff, which may compromise patient care. Refusal might also have medicolegal implications if subsequent patient morbidity or death could be attributed to withholding of the transfusion.

For sustained improvement in practice, prospective monitoring must be continued indefinitely [11]. This is both time consuming and demanding of staff. The demand might be lessened by computerized audit of transfusion requests; clinical and laboratory data could be entered into a program which flags non-compliant requests for review by blood bank staff.

\section{Conclusion}

In conclusion periodic review of blood component usage is very important to access the blood utilization pattern in any hospital and judicious implementation of guidelines for use of various blood components may help decrease their inappropriate use. This will ensure availability of components to needy patients and save many patients. From transfusion related reactions also. Awareness and education among all those treating doctors and establishment of guidelines in wards and, regular audit will prove a fruit full exercise to increase the appropriate use of blood and blood components to $100 \%$.

\section{References}

1. Metz J, McGrath KM, Copperchini ML, Haeusler M, Haysom HE, et al. (1995) Appropriateness of transfusions of red cells, platelets and fresh frozen plasma. An audit in a tertiary care teaching hospital. Med J Aust 162: 572-577.

2. Tuckfield A, Haeusler MN, Grigg AP, Metz J (1997) Reduction of inappropriate use of blood products by prospective monitoring of transfusion request forms. Med J Aust 167: 473-476.

3. Luk C, Eckert KM, Barr RM, Chin-Yee IH (2002) Prospective audit of the use of fresh-frozen plasma, based on Canadian Medical Association transfusion guidelines. CMAJ 166: 1539-1540.

4. Toy PT (1996) Audit and education in transfusion medicine. Vox Sang 70: 1-5.

5. Barnette RE, Fish DJ, Eisenstaedt RS (1990) Modification of fresh frozen plasma transfusion practices through educational intervention. Transfusion 30: 253-257.

6. Vishwanathan C, Jain R, Kamath M (1999) Blood utilization review in a tertiary care hospital. Indian J Haematol Blood Transf 17: 26-31.

7. Solomon RR, Clifford JS, Gutman SI (1988) The use of laboratory intervention to stem the flow of fresh frozen plasma. Am J Clin Pathol 89: 518-521.

8. Brien WF, Butler RJ, Inwood MJ (1989) An audit of blood component therapy in a Canadian general teaching hospital. Can Med Assoc J 140: 812-815.

9. Shanberge JN, Quattrociocchi-Longe T (1992) Analysis of fresh frozen plasma administration with suggestions for ways to reduce usage. Transfus Med 2: 189-194.

10. Simpson MB (1987) Prospective concurrent audits and medical consultation for platelet transfusions. Transfusion 27: 192-195.

11. Silver H, Tahhan HR, Anderson J, Lachman M (1992) A non- computer dependent prospective review of blood and blood component utilization. Transfusion 32: 260-265.

12. Brandis K, Richards B, Ghent A, Weinstein S (1994) A strategy to reduce inappropriate red blood cell transfusion. Med J Aust 160: 721-722.

13. Joshi GP, Landers DF (1998) Audit in transfusion practice. J Eval Clin Pract 4 141-146.

14. Cheng G, Wong HF, Chan A, Chui CH (1996) The effects of a self-educating blood component request form and enforcements of transfusion guidelines on FFP and platelet usage. Queen Mary Hospital, Hong Kong. British Committee for Standards in Hematology (BCSH). Clin Lab Haematol 18: 83-87.

15. Marconi M, Almini D, Pizzi MN, Riccardi D, Bergamaschi W, et al. (1996) Quality assurance of clinical transfusion practice by implementation of the privilege of blood prescription and computerized prospective audit of blood requests. Transfus Med 6: 11-19. 